\title{
Unprecedented Times and Innovation
}

\section{Claire Major $^{1}$}

Accepted: 12 October 2020 / Published online: 23 October 2020

(C) Springer Nature B.V. 2020

The COVID-19 pandemic has had a profound effect on the lives of people around the world. The continued threat of the disease has led to ongoing changes and challenges, requiring us to quickly adapt to different ways of working, learning, and connecting with each other. The virus has, simply put, disrupted the status quo, and it has been unlike anything we've experienced in modern times. Many of us have received emails, dozens of them, from our institutions, from every company we've ever interacted with (and some we haven't), and even from friends and family that begin with the proclamation that we are living in "unprecedented times." The term is not a particularly poetic one, but it has suddenly become so common that it is beginning to border on cliché. I've used the term myself, and I feel fairly confident that I'm not alone in falling back on a cliché to express what seems, for the most part, inexpressible. While cliché may be thought of something that is overused or unoriginal, it may also be considered a kind of linguistic shorthand intended to save time when we refer to thoughts and experiences so common that they become almost elemental to our shared understanding. So, what exactly are we saying when we use this phrase? What common human experience are we trying to communicate?

Merriam-Webster documents the first use of the term "unprecedented times" around 1795. Although this term has been around for two centuries, its use has increased over time. Along the way, there have been three distinct usage peaks. According to a Google nGram (a tool that allows you to see how words and phrases have been used over time based on their occurrence in the over 30 million print books that Google has scanned), the first peak occurred in 1814/15. This peak coincided with the end of the Napoleonic wars and the end of the War of 1812; it also corresponded with the beginning of the Era of Good Feelings in the United States. The second peak occurred in 1818/1819, contemporaneous with the flu pandemic and the end of World War I and just prior to the roaring 20s and developments in Women's Suffrage. And the most recent peak, before now, was in 1945, marking the end of WWII and the founding of the United Nations. Thus, while increased usage of the term has coincided with some decidedly challenging times in our history, the peaks also reflect new beginnings of prosperity, growth, and innovation.

Claire Major cmajor@ua.edu

1 Higher Education Administration, The University of Alabama, Tuscaloosa, AL 35487, USA 
What do we mean by "unprecedented times" in our current usage? The word "unprecedented" is formed from the noun "precedent," which refers to something done or said that is used as an example to be followed in the future. The term comprises the prefix "un," which means "not," the noun "precedent," and the suffix "ed," which means "having." It is an adjective that means "having no precedent," "without previous instance," and "never before known or experienced." Trying to parse out the meaning of the word unprecedented, it seems to me that it takes on different meaning according to context. I offer the following synonyms for "unprecedented," organized in a way intended to communicate a range of potential meaning:

\begin{tabular}{lll}
\hline & More positive & Less positive \\
More formal & Extraordinary & Abnormal \\
& Uncommon & Anomalous \\
& Unequaled & Eccentric \\
& Unmatched & Idiosyncratic \\
& Unparalleled & Odd \\
Less formal & Unrivaled & Untypical \\
& New & Bizarre \\
& Novel & Crazy \\
& One of a kind & Freakish \\
& Unheard of & Weird \\
\hline
\end{tabular}

As an adjective, "unprecedented" is necessarily paired with other words. It often is modified by an adverb, and common adverbs associated with "unprecedented" include "almost," "nearly," and "virtually," as well as "wholly," "totally," and "utterly." Nouns that are frequently modified by the adjective "unprecedented" tend to be positive. They include "opportunity," "prosperity," "accuracy," and "growth." Other frequently associated nouns are more neutral: "pace," "scale," and now "times," the latter of which means the indefinite continued progress of existence and events in the past, present, and future regarded as a whole. Synonyms include age, moment, era, season, epoch, eternity, and lifetime. Thus, I believe what we mean when we say that these are "unprecedented times" is that we are in a "wholly, totally, utterly" "unparalleled, abnormal, freakish, weird" "age, moment, season."

We are in an evolving situation, and the full effect of these unprecedented times remains unclear. What is clear is how effective many institutions of higher education and their faculty and staff have been in innovating in order to serve not only their students but also their communities. It is during unprecedented and yes challenging times that innovation can thrive, and innovation for the future is more important than ever. From small acts of kindness to tracking important data, the last few weeks and months have shone a bright light on the power of human creativity and collaboration and community. Let's take a deep and appreciative breath together on that.

\section{Further Reading}

Merriam-Webster. (2020). Usage of unprecedented. https://www.merriam-webster.com/words-atplay/precedented-and-unprecedented-times

Publisher's Note Springer Nature remains neutral with regard to jurisdictional claims in published maps and institutional affiliations. 